\title{
IEDER MENSCH GENEALOGISCH BEPAALD, EEN VOORSTEL TOT ALGEMEENE STAMBOOMREGELING
}

\author{
DOOR \\ Dr. M. BOISSEVAIN \\ BILTHOVEN.
}

Het erfelijkheids-onderzoek bij den mensch neemt jaarlijks toe, niettegenstaande de moeilijkheden, die eraan verbonden zijn, en die vooral voortvloeien uit de onmogelijkheid, kweekproeven in te stellen, waardoor men enkel is aangewezen op statistische gegevens en een uitgebreid familie- en stamboomónderzoek.

Men zou kunnen betoogen, dat men de wetten der erfelijkheid bij planten en dieren zooveel mogelijk zou kunnen trachten op te sporen, zij zullen blijken, ook bij den mensch evengoed geldig te zijn, doch daargelaten, dat dan een buitengewoon vruchtbaar, zoo niet het allervruchtbaarste veld van onderzoek verloren zou gaan, zou men ook geen gelegenheid hebben, het ingewikkelde organisme, dat de menschelijke staat is, te bestudeeren. Zoo als men den bijenstaat niet kan begrijpen zonder een uitgebreide biologische kennis van de bij, evenmin zal men den menschelijken staat begrijpen zonder kennis van den mensch.

Het nationale karakter van een volk, het ingewikkelde en tegenwoordig zoo nijpende bevolkingsprobleem - de degeneratie en opbloei van een volk, de sociale verschijnselen zooals pauperisme, prostitutie, criminaliteit, alcoholisme, ja, oorlog, en vrede, het zijn alle in den grond biologische vraagstukken, wier oplossing alleen nader gebracht kan worden door de kennis der wetten, waarlangs de menschheid in de opeenvolgende generaties zich voortbeweegt. De rassenvermenging en het optreden van erfelijke gebreken en ziekten, het zijn eveneens punten, die slechts bij en aan den mensch onderzocht kunnen worden.

- De geheele menschheid is op te vatten als één groote familie. Denkt men zich slechts een voldoend aantal generaties terug, dan kan men voor ieder willekeurig paar menschen gezamentlijke voorouders vinden. Dit feit heeft op zichzelf niets bizonders, het treedt evenwel in veel sterker mate op, dan men zich gewoonlijk voorstelt. Als men bedenkt, dat een tegenwoordig levend mensch ten tijde van Karel den Groote, dus ongeveer 11 eeuwen geleden, het theoretische aantal van $2^{33}$ of wel ruim 8000 millioen voorouders moet bezitten, dan blijkt, dat dit theoretische aantal alleen omgezet wordt in het feitelijke aantaI door het voorkomen van huwelijken van personen, die reeds gemeenschappelijke voorouders bezaten, door z.g. inteelt dus.

Men kan nu betrekkelijk gemakkelijk uitrekenen, hoeveel verwantschapshuwelijken er gedurende een aangenomen aantal generaties bij een bevolking, afstammende van een bekend aantal zielen, minstens moeten plaats hebben, om het theoretisch aantal voorouders te doen inkrimpen, tot het werkelijk mogelijke aantal.

Bij bevolkingen, die ethnografische eenheden vormen, moet daarom het bloed in den loop van een tiental eeuwen reeds zoo vermengd zijn, dat vele stamouderparen tot zelfs over de duizende malen in de stamreeks van alle bewoners zullen voorkomen.

Het ligt voor de hand, hieruit de gevolgtrekking te maken, dat het nationale karakter van een volk door deze inteelt in hoofdzaak bepaald zal zijn geworden. Maar behalve in naties zijn alle volken 
steeds onderverdeeld in groepen, kasten, klassen of standen, organische eenheden zoo men wil, die ook weder op hun beurt onderhevig zijn aan zekere mate van inteelt, maar die tevens een voortdurende wisselwerking op elkander uitoefenen, zoodat telkens leden van de ééne klassé opgenomen worden in de andere, hetzij hoogere of lagere. Deze mutaties hangen ten nauwste samen met het geheele bevolkings-probleem, een probleem, veel ingewikkelder dan bij de bijen, maar de „Dzierzon" moet nog komen, om voor ons menschen de ware verhoudingen op te speuren en te verklaren.

Eerst de kennis omtrent het genetisch verband, dat tusschen de groepen onderling bestaat, zal ons licht kunnen geven in deze voor 't oogenblik nog duistere problemen.

Evenmin als de medische wetenschap in de toekomst denkbaar is zonder den mensch in verband met zijn afstamming te beschouwen, zoo zullen ook de sociale wetenschappen meer en meer verband met de genealogie moeten gaan zoeken. Langs den weg der statistiek alleen zal 't niet mogelijk zijn aan te toonen, waarom b.v. de krankzinnigheid in een land toeneemt of hoe de welstandscurven van families over meerdere generaties verloopen, of waarvandaan de bewoners van een Londensche "slum" stammen, hoevele generaties zij het er uithouden, welk procent er boven uitstijgt om slechts enkele voorbeelden te noemen.

Onze kennis omtrent het genetisch verband der menschen is nu nog uiterst gering. Meestal is het onherroepelijk verloren gegaan in het verleden, in verhouding tot de geheele menschheid is het slechts hier en daar sporadisch aangeteekend gebleven en de genealogische aanteekeningen, die wij bijeen kunnen verzamelen, zijn ontoereikend, om ons de groote lijnen te doen zien, waarlangs het menschelijk geslacht zich ontwikkeld heeft.

De genealogie- in haar tegenwoordigen vorm heeft weliswaar belangrijke diensten bewezen en het in de laatste jaren sterk toegenomen erfelijkheids-onderzoek bewijst, dat er op dat gebied door particulier initiatief en onderzoek wel wat te bereiken is. Talrijke families bezitten stamboomen, die op meerdere generaties teruggevoerd worden, - sommige daaronder, zooals de meeste vorstengeslachten, gaan ettelijke eeuwen terug. In vele landen heeft men sinds het begin der vorige eeuw een Burgelijken Stand ingevoerd en in de meeste beschaafde landen heeft op de een of andere wijze een registratie van geboorte en overlijden plaats, zoodat met eenige moeite en geduld de namen van ouders, grootouders en misschien overgrootouders van iemand wel te vinden zijn. Vóór dien tijd moet men zich bepalen tot de aanteekeningen in alle mogelijke staats-, gemeente- en andere archieven, in kerkboeken, particuliere bijbels, familiepapieren etc.

Het groote bezwaar blijft evenwel steeds, dat - mocht het ook na veel napluizen gelukken, een lange reeks voorouders op te speuren - de feitelijke bijzonderheden omtrent de personen, juist datgene, wat men weten wil, uiterst karig voorhanden zijn en daarbij dikwijls niet betrouwbaar of onvolledig zijn.

Wat langs dezen weg bereikt kan worden, staat in geen verhouding tot wat men omtrent de geheele erfmassa van een volk zou wenschen te weten. De draden der menschelijke afstamming liggen verward door elkander in een ondoordringbaar kluwen en steeds spint zich het net voort in al breedere strooken van zich verdubbelende voorvaderrijen. Zal het mogelijk blijken, die draden vast te grijpen en te ordenen naar onze hand, het verwarde net, voor de toekomst althans, tot een regelmatig weefsel met duidelijke figuren uit te spreiden?

In sommige landen is men reeds begonnen, het familie-onderzoek en geslachtsboom-registratie meer systematisch ter hand te nemen. In Engeland is dit het eerst begonnen door GALTON, den grondlegger der Eugenetica, met door hemzelf onder talrijke families ingestelde enquêtes, welk werk zich naderhand uitbreidde tot het "Laboratory for National Eugenics," aan welks hoofd thans KARL PEARSON staat. In "The Treasury of Human Inheritance" zijn reeds een groot aantal uitkomsten van een uitgebreid familie-onderzoek openbaar gemaakt.

Het is misschien hier de plaats, een enkel woord over de eugenetische leer te zeggen, daar deze in ons land bij velen ten onrechte een impopulaire klank heeft gekregen. Grootendeels is dat te wijten aan de al te snelle toepassing van maatregelen omtrent huwelijksverbod en sterilisatie in sommige Staten van Noord-Amerika, terwijl ook een richting in Duitschland om met behulp van staatsprotectie een soort model-burgers te gaan kweeken, in Nederland wel niet veel aanhangers zal vinden. GaLToN's 
opzet is geen andere geweest, dan de omstandigheden te leeren kennen, waaronder de raseigenschappen van den mensch, de geestelijke zoowel als de lichamelijke, zich op de beste wijze ontplooien en voortplanten konden. Hij was zich bewust van het onderscheid tusschen eigenschappen, welke aangeboren zijn en die van de omstandigheden afhankelijk zijn. Zijn termen "nature” en „nurture”, de erfelijke aanleg en de omstandigheden, worden door zijn navolgers in Engeland nog steeds meer gebruikt dan de termen genotypie en phaenotypie. GALTON in 1874 schrijvende over den invloed van "nature" en "nurture” op het wezen van den mensch, verklaart, dat „nature” in de meeste gevallen zal blijken het sterkste te zijn. Door de verhouding dezer twee krachten na te gaan, hoopte hij de middelen te vinden, om op den duur een beter, gezonder, sterker en geestelijk hooger staand menschenras te kweeken, en hij meende dat door het bevorderen van oordeelkundige huweiijken een selectie in de goede richting verkregen zou worden. Van een direct ingrijpen in de genotypische gesteldheid eener bevolking is bij GALTON nooit sprake geweest.

En daarvoor zijn onze kennis en vooral ook ons dieper inzicht in de menschelijke verhoudingen nog veel te ontoereikend. Mogen wij nog in 't schoone sprookje gelooven, dat alle menschen gelijk zijn en welgeschapen en zedelijk gezond zouden zijn, indien de omstandigheden voor allen gelijk gelukkig zouden zijn; of zijn er soorten van mismaaktheid, krankzinnigheid, misdadigheid, ziekelijkheid, die van geslacht tot geslacht onveranderd worden voortgeplant en niet voor verbetering vatbaar zijn. En indien de menschen naar hun erfelijke eigenschappen ongelijk zijn, indien er minder- en meerwaardigen zijn, welke planten zich dan het sterkste voort?

Is het waar, dat toenemende beschaving gepaard gaat met verminderde vruchtbaarheid, welke beteekenis heeft dat dan voor de geheele erfmassa van een volk, blijft deze onveranderd, voortdurend vernieuwd uit de lagen der primitievere bevolking, die een onuitputtelijke bron van zich gelijk blijvende erfmassa zou zijn, of gaat een volk langzaam aan eigen beschaving te gronde? En benauwend dringt de vraag naar voren, of de sociale maatregelen, die de zwakken en minderwaardigen beschermen, noodzakelijk het degeneratieproces versnellen.

In alle beschaafde landen worden deze vragen thans aan de orde gesteld en het is de eerste opgave der eugenetica, de gegevens te verzamelen voor een zoo omvangrijk mogelijke demografie, waarbij de mensch niet alleen als individu, maar in zijn familieverband, verloopende over meerdere geslachten, beschouwd worde.

In de Vereenigde Staten bestaat sinds 1910 het bekende „Eugenic's Record Office”, onder leiding van Charles DavenPort, dat zich ten doel stelt het verzamelen en systematisch verwerken van alle gegevens, die betrekking hebben op de genetische gesteldheid van het Amerikaansche volk. Men werkt er deels met uitvoerige vraaglijsten, deels met z.g. „Fieldworkers”, die de opdracht krijgen, bij verschillende families ter plaatse de noodige inlichtingen te verzamelen.

In Duitschland zijn van verschillende zijden stemmen opgegaan, om de familie-documentatie door den staat te doen geschieden. SChallmaYeR stelt voor, de invoering van verplichte z.g. „Personalbogen" waarin met behulp van daarvoor aangestelde artsen op geregelde tijden de noodige aanteekeningen over lichamelijke en geestelijke eigenschappen ingevuld zouden moeten worden. De „Personalbogen” zouden op den duur aangroeien tot „Familieboeken”, die bij ziektegevallen en vòòr het sluiten van huwelijken geraadpleegd konden worden. Ook Tugendreich, MaX v. Gruber, Crzellitzer, SOMMER en RüDIN hebben voorstellen in dezelfde richting gedaan en van meerdere zijden wordt aangedrongen op registratie van alle erfelijke ziekten en abnormaliteiten. Onder RüDIN's leiding is gesticht een genealogisch-demografische afdeeling van de nieuwe „Forschungsanstalt für Psychiatrie”.

In Zweden wordt in die richting gewerkt door den psychiater LUNDBORG, die in zijn standaard werk ruim 2000 personen uit een Zweedsche boerenfamilie biologisch-medisch beschrijft. Hij heeft ongeveer 20 jaren noodig gehad, om het materiaal bij elkaar te verzamelen en aan 't eind van zijn werk spreekt hij den wensch uit, dat in alle landen centrale genealogische instituten mogen verrijzen, om het erfelijkheidsonderzoek op groote schaal mogelijk te maken en te vereenvoudigen.

Sindsdien is in 1918 in Zweden opgericht het "Nobelinstituut voor Rassenbiologie".

In ons land hebben wij het: bekende werk van Dr. J. J. TH. Doyer over Erfelijkheid en Tuberculose Ook Dr. Doyer ondervond de bezwaren, verbonden aan het familie-onderzoek onder een ongeletterde bevolking, niettegenstaande hij uitging van kinderen, niet ouder dan 8, 9 en 10 jaren en 
alleen de ascendenten tot in de 3 de generatie, in enkele gevallen tot in de 4 de generatie naging, waarbij hij in de gelegenheid was, eigenhandige aanteekeningen over die personen in den loop van zijn dokterspraktijk gemaakt, te benutten.

Welk een oneindig voordeel zou het zijn, voor alle erfelijkheidsonderzoek op 't gebied van biologie en sociologie, van medische wetenschap en anthropologie, indien 's menschen afstamming opgeteekend en bewaard kon blijven met een beknopte persoonsbeschrijving.

Is een dergelijk plan theoretisch mogelijk, praktisch uitvoerbaar?

Theoretisch is het eigenlijk niet ingewikkeld, het is eerder eenvoudig te noemen. Wil men de begindraadjes der tegenwoordige generatie vastgrijpen, dan zou men - en ik laat nu alle beeldspraak varen - de tegenwoordig levende menschen, de stamouders der komende geslachten, genealogisch moeten registreeren volgens een bepaalde nummering. De nummers, aan deze stamouders gegeven, zouden de stamnummers blijven van alle komende geslachten, er zouden geen nieuwe bijkomen, ieder afstammeling zou een kwartierstaat bekomen, bestaande uit combinaties dezer eenmaal gegeven nummers. Dat de tegenwoordige familienamen hiervoor minder geschikt zijn, spreekt vanzelf, als men bedenkt, hoeveel eensluidende namen er bestaan. Registreert men volgens nummers, dan voorkomt men niet alleen alle persoonsverwisselingen, doch men kan tegelijkertijd reeds volgens de nummers de stamouders in groote groepen onderverdeelen, volgens stad en land, of volgens de gemeenten, de rassen en nationaliteiten, 't geen voor administratieve doeleinden praktisch, maar ook voor het verkrijgen van een snel overzichtelijk beeld van iederen kwartierstaat van groot gemak zou zijn.

Zijn eenmaal alle op een zeker tijdstip levende stamouders volgens nummers geregistreerd, dan bekomen hun kinderen in hun kwartierstaat het nummer van den vader en de moeder met daarbij aangegeven het hoeveelste kind zij zijn.

Gesteld de nummering werd in Nederland ingevoerd, dan zouden van de plm. 7 millioen inwoners ongeveer 3 millioen mannen en vrouwen, de ouders der resteerende 4 millioen, genummerd moeten worden. Een kind zou dan de beide nummers zijner ouders ontvangen en b.v. de genealogische formule:

$$
\text { - } \left.\begin{array}{r}
2.798526 \\
1.307824
\end{array}\right\} 4
$$

bekomen. Hiermede is dat kind genealogisch bepaald. Slechts zijn broeders en zusters bezitten dezelfde nummers, doch met andere rangcijfers en zijn daarom duidelijk onderscheiden. Het kind is genealogisch bepaald, daar geen ander -- ook niet in komende generaties - dezelfde formule kan dragen. Treedt n.l. die persoon in het huwelijk, dan zullen zijn kinderen weer den gecombineerden kwartierstaat van hem en zijn vrouw ontvangen en het eerste kind b.v. de formule:

$$
\begin{aligned}
& 1.762375
\end{aligned}
$$

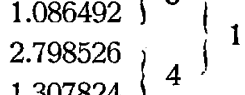

bekomen - en zoo steeds verder, zoodat een kwartierstaat van 4 generaties, ingevuld op een geboortebewijs, er als volgt zou kunnen uitzien:

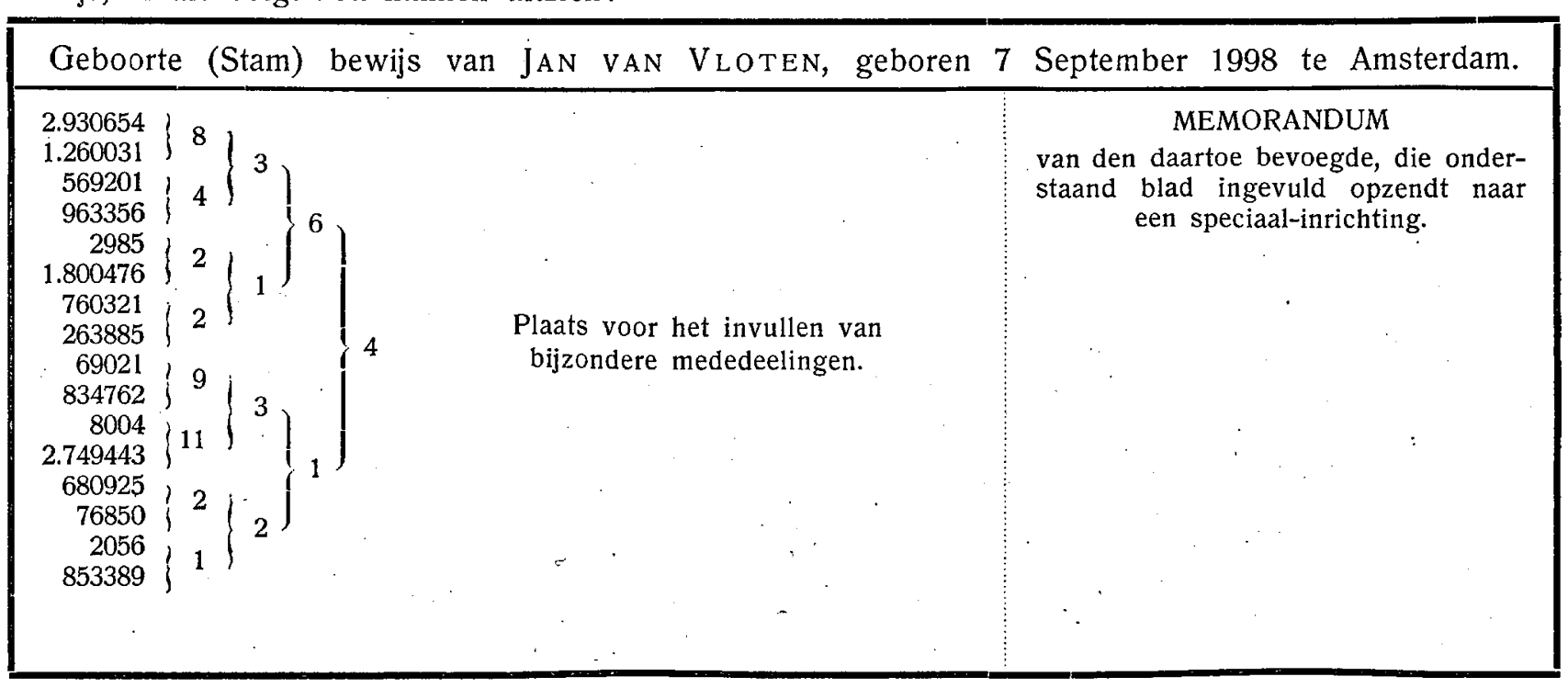


Werd het nu zoo ingericht, dat ieder op zijn geboortebewijs zijn kwartierstaat afgedrukt bekwam, dan zou men dus zonder moeite de afstamming van ieder mensch in handen krijgen. Evenwel de afstamming alleen is niet voldoende, het is juist te doen om uitvoerige en vooral nauwkeurige persoonsbeschrijvingen. Dit zou langs twee wegen kunnen geschieden. In de eerste plaats zou het verplicht gesteld kunnen worden, voor ieder persoon b.v. drie maal in zijn leven een vragenlijst te beantwoorden, die naar een centraal bureau opgezonden en daar volgens de nummering bewaard werd.

In het bovenstaande geval zou Jan van Vioten te vinden zijn onder het nummer van zijn mannelijke linie 853389, dat onderaan staat, de afstamming van zijn moeder ware na te gaan onder 263885 . Ook zijn moeders vader en grootvader zijn onder dat nummer te vinden enz.

De andere weg, die met den eersten te combineeren ware, zou rechter op 't doel afgaan. Men zou n.l. de van'kwartierstaten voorziene geboortebewijzen - die dan evenwel met meer recht den naam van stambewijzen zouden dragen - in meerdere bladzijden kunnen afdrukken, in den geest van bonboekjes.

Voor alle speciale gevallen zouden dan afzonderlijke bladzijden ingevuld en naar de betreffende instituten opgezonden kunnen worden, om daar eventueel dadelijk of later, genealogisch verwerkt te worden. Op die manier zou een begin worden gemaakt met de registratie van alle voorkomende bijzondere gevallen, zooals psychische defecten, doofstomheid, kleurenblindheid, etc. Maar men zou ook. het voordeel hebben, dat men zonder buitengewone moeite iedere categorie van menschen naar hun afstamming zou kunnen registreeren, b.v. de door den staat-veroordeelden, de ingeschreven prostituées, het zou zelfs de gewoonte kunnen worden, in de ziekeninrichtingen de ziektegeschiedenissen te bewaren, met een daaraan vastgehecht stambewijs.

Een ander voordeel van deze inrichting zou zijn, dat daardoor de groote opeenhooping van materiaal in het centraal bureau voorkomen zou worden, want het is wel eenigszins beangstigend, te bedenken, wat men allemaal van een mensch moet weten, als men zijn beeld, al is 't ook maar in groote trekken, voor het nageslacht bewaren wil.

DAVENPORT heeft in zijn "Traitbook" ons daaromtrent uitvoerige uiteenzettingen gegeven. Ook LORENTZ in zijn bekende "Lehrbuch” heeft eenige regels aangegeven voor een beknopte persoonsbeschrijving, die in 6 rubrieken onder te verdeelén zou zijn:

1e. zuiver biologische feiten (levensduur, aantal kinderen)

2e. morphologische beschrijving (lichaamsbouw, schedelvorm, kleur van huid, haar en oogen, etc.)

3e. bijzondere eigenschappen (abnormaliteiten)

4e. bewegingswijze (gelaatsuitdrukking, handschrift?)

5e. ziekten en doodsoorzaak.

6e. geestelijke eigenschappen (temperament, deugden, ondeugden, voorliefden, talenten, etc.).

Hier zou dan nog een 7 de rubriek aan toegevoegd kunnen worden voor de sociale wetenschappen, als welstand, beroep, maatschappelijke positie, godsdienst, etc.

Ieder dezer categoriën is natuurlijk tot in het oneindige op te voeren en het is daarom wenschelijk, dat er met mate en bescheidenheid te werk gegaan wordt, om de eventueel verplichte vragenlijst niet onnoodig lang te maken, waardoor zij den menschen tot een last zou worden. Is daarentegen iemand onder behandeling van een arts of specialist, dan is het een geringe administratieve moeite, enkele bijzonderheden naar het daarvoor bestemde instituut op te sturen. Het Centraal Bureau werd dan ontlast van, een zeer groot deel der werkzaamheden en kon zich bepalen tot het drukken en administreeren der stambewijzen en algemeene vragenlijsten.

Werden de kwartierstaten van alle menschen bijgehouden, dan zouden de stamboomen daaruit afgeleid kunnen worden en volgens de methode van CRzellitzer, Sommer e. a. ware het mogelijk, den verwantschapsgraad van alle personen aan te geven.

Reeds bij een oppervlakkige beschouwing van iederen kwartierstaat ware dadelijk te onderkennen:

1e. de graad van inteelt bij de voorouders;

$2 \mathrm{e}$. de rassenvermenging;

3e. alle andere bijzonderheden, die eventueel bij de oorspronkelijke nummering werden aangegeven, zooals de verdeeling naar oorsprong uit stad of land, etc.

Een niet te 'onderschatten bezwaar bij het maken van stamboomen op groote schaal ligt natuurlijk 
in het feit, dat bij een aantal geboorten de naam van den vader verkeerd wordt opgegeven. Ditzelfde bezwaar kleeft eenigermate alle genealogisch onderzoek aan. Men zal dus steeds voorzichtig moeten zijn met het beoordeelen der resultaten en niet alleen uit enkele gevallen besluiten mogen trekken, maar juist door de groote massa van 't materiaal zal 't allicht mogelijk zijn, fouten te ontdekken en uit te schakelen.

Tot zoover de theorie. Wat de praktische uitvoerbaarheid betreft, daarover zal ik hier niet te ver uitweiden.

Ik zie in dezen tijd van algemeene bezuiniging reeds bedenkelijke gezichten bij het denkbeeld, om een nieuwe staatsdienst in 't leven te roepen.

Zoover zijn wij ook nog niet.

Het is een zaak, die grondige voorbereiding noodig heeft en liefst in samenwerking met andere landen moet geschieden. Bij de talrijke internationale huwelijken en de rassenvermenging op groote schaal, die tegenwoordig plaats heeft, zou eenheid van uitvoering in het systeem zeer gewenscht zijn. Allereerst moet de belangstelling der vakgenooten zelve ervoor gewonnen worden.

Hopelijk zal dit onderwerp een punt van bespreking mogen uitmaken op het derde Internationale Eugenetisch Congres, dat in 1924 misschien wel in Nederland zal worden gehouden.

Het is een arbeid, waar het nageslacht eerst grootendeels de vruchten van zal kunnen plukken, maar in dit opzicht mogen wij gedachtig zijn aan onze voorouders, die de statige beukenalleeën geplant hebben, niet om zichzelven in de schaduw te vermeien, maar om hun nageslacht van dienst te zijn. 


\section{LITTERATUURLIJST.}

1. BAuR, (Erwin) Fischer (Eugen) und Lenz (Fritz). Menschliche Erblichkeitslehre. 1 Bd. 1921. München (Bd. II en III nog niet verschenen)

2. BREYMANN. Ueber die Notwendigkeit eines Zusammengehens von Genealogen und Medizinern in der Familienforschung. Arch. f. Rassen u. Gesellsch. Biologie Bd. IX 1912

3. BuRgdorfer, Fr. Das Bevölkerungsproblem seine Erfassung durch Familien-Statistik und Familien-Politik. München 1917.

4. Crzellitzer. Die Berliner Familienstammbücher und ihre Ausgestaltung für die Zwecke der Vererbungsforschung und sozialen Hygiene. Halbmsch. f, soz. Hyg. 19i1. N ${ }^{n} .12$.

5. DAVENPoRT, Dr. C. B. Importance of heredity to the State Quarterly representing the Minnasota educational philantropic correctional and penal inst. Vol. $12 \mathrm{~N}^{\circ} .2$.

-... The Trait Book Eug. Rec. Off. Bull. N". 61912

- The Family History Book Eug. Rec. Off. Bull. No. 7.

- and Laughlin. How to make a eugenic family study. Eug. Rec. Off. Bulletins N". 13.

- Laughlin, Weeks, Johnstone, Goddard. The Study of human heredity, methods' of collecting charting" and analyzing data Eug. Rec. Off. Bull. No 2. Zie verder alle Eug. Rec. Off. Bull.

6. Dannemann. Der Kurs über Familienforschung und Vererb. lehre zu Giessen. Mitt. der Zentr. Stelle f. deutsche Personen und Familien Geschichte 1909 Hft. 5.

7. Devrient, Ernst. Familien forschung. Aus Natur und Geisteswelt Teubner 1919

8. DOYER, J. J. Th. Tuberculose en Erfelijkheid. Wolters Groningen 1920

9. DONCASTER, L. Heredity in the light of recent research. Cambridge Univ. Press. 1910.

10. Eugenics Record Office Bulletins Long Island. N. Y.

- Problems in Eugenics, Papers communicated to the First Intern. Eugenics. Congress London July 24-30 1912. publ. by Eugen. Educ. Soc. 1912 .

11. FAMILIEN Geschichtliche, Blätter. Monatschrift zur Förderung der Familien Geschichtsforschung. Verlag H. A Degener, Leipzig.

12. Forst, Otto. Genealogische Tafeln. Handbuch der prakt. Genealogie von Heydenreich. p. 42.1913.

- Genealogie Meisters Grundrisz der Geschichtswissenschaft I 4a. Teubner, Berlin.

13. Frets, G. P. Erfelijkheid en Eug. Sociale Gids 1918.

14. Galton, P. Inquiries into Human Faculty and its Development. Goedk. ed. J. M. Dent.

- Natural Inheritance. Macmillan 1889.

- Essays in Eugenics. Eugenics Education Soc. London 1909.

- Hereditary Genius. Macmillan 1869.

- English Men of Science. Their nature and nurture. Macmillan 1874

i5 Gruber, Max v. Vererbung Auslese und Hygiene Mediz. Wochenschrift 1909.

- Organisation der Forschung und Sammlung von Materialien über die Entartungsfrage. Concordia 1910 en overgenomen in: Soziale Praxis und Archiv für Volkswohlfahrt nr. 43 (1910).

- - und Rüdin. Fortpflanzung, Vererbung und Rassenhygiene. München 1911. Lehmans Verl.

16. GRotjahn, A. Jahresbericht über soziale Hygiene und Demographie. Jena. vanaf 1901.

17. HeydenREICH, Eduard. Handbuch der praktischen Genealogie in Verbinding met v. Dungern, Karge, Rob. Sommer, Forst-Battaglia, Mucke end Tille. Leipzig 1913

18. Hoffmann, Geza v. Die Rassenhygiene in den Vereinigten Staaten von Nord-Amerika. Lehm. Verl. München 1913.

19. KekUlé von STRAdonitz. Ueber eine zweckmässige Bezifferung der Ahnen. Vierteljahrschrift f. Wappen-, Siegelund Familienkunde 1898.

20. KraePelin. Zur Entartungsfrage. Zentralbl. für Nervenheilk. u. Psych. 1908, 2 Oktober Heft.

21. LORENZ, O. Lehrbuch der wisschenschaftlichen Genealogie. Berlin 1898.

22. Lotsy, J. P. Sur les rapports entre des problèmes sociaux et quelques résultats de la théorie moderne de l' hérédité. Arch. Néerl. Sc. exactes et nat. Ser. III B 3, p. 151, 1916.

23. LUNDBORG, H. Medizinisch-biologische Familienforschungen innerhalb eines 2232 köpfigen Bauerngeschlechtes in Schweden. Jena 1913

24. MAANEN, J. F. van. Wetenschappelijke Genealogie. Rijswijk 1901.

25. ODIN, A. Genèse des grands hommes. Paris 1895

26. Popenoe, P. Genealogy and Eugenics. Journ. Heredity 6. 1915. 
27. Pearson, K, The scope and importance to the State of the Science of national Eugenics. Galton Laboratory Lecture Series 1911.

- Nature and nurture the problem of the future. Dito.

- The problem of practical Eugenics. Dito.

28. Roemer, Dr. Hans. Eine Stammliste usw. Psych.--Neurol. Wochenschr. 13 Jahrg. nr. 10.

- - Ueber Psychiatrische Erblichkeitsforschung Arch. f. Rassen u. Gesellsch. biol. Jahrg. IX 1912.

_- Zur Reform der deutschen Irren-Statistik. Arch. f. Sociale Hygiene und Demographie Bd. 9. H. 3 u. 4.

29. Roller, Otto Konrad. Die Einwohnerschaft der Stadt Durlach im 18 Jahrhundert in ihren wirtschaftlichen und kulturgeschichtlichen Verhältnisse, dargestellt aus ihren Stammtafeln. Karlsruhe 1907.

30. Rübin. Einige Wege u. Ziele d. Familienforschung mit Rucksicht auf die Psychiatrie. Zeitschr. f. d. ges. Neur. u. Psych. Bd. 7 H. 5 (1911).

31. Schallmayer, W. Vererbung und Auslese. 4te Aufl. Jena 1920.

- - Ueber die drohende körperliche Entartung. Neuwied. 1891.

- Ein Medizinalministerium. In der Kölner Wochenschrift, Das neue Jahrhundert 1899.

- Neue Aufgaben und Organisation. der Gesundheitspolitik. Arch. für Soziale Hyg. und Demographie Bd. 13. Hft. 31919.

32. SMith, G. E. Man's pedigree. Journal Heredity 5. p. 377.

33. SOMmer, R. Psych. Neurol. Wochenschrift 7 Jahrg. Nr. 31 en 8 Jahrg. Nr. 4.

- Ein Reichinstitut für Familienforschung, Vererbungs und Regenerationslehre. Die Grenzboten $1912 \mathrm{Nr} .12$.

- Familienforschung und Vererbungslehre. 1907.

_- Familiengeschichtliche Quellenkunde im Gebiete der Psychiatrie und Anthropologie. Handb. der prakt. Gen von Heydenreich.

34. Steinmetz, S. R. Die neueren Forschungen zur Geschichte der Familie. Ztschr. f. Sozialw. 1899.

- Der. erbliche Rassen und Volkscharakter. Vierteljrsch f. Wiss. Phil. u. Soziol. 1902.

35. Tille; Dr. Armin. Genealogie und Sozialwissenschaft. Handbuch der prakt. Genealogie von Heydenreich T. I. S. 371.

- Genealogie als Wisschenschaft. Mitteilungen der Zentralstelle f. deutsche Personen und Fam. Geschichte Heft 2 (1906).

- Die Sozialwissenschaftliche Bedeutung der Genealogie. Ebenda Heft 6 (1910).

36. Treasury of Human Inheritance, uitgeg. door het Galton Laboratory f. National Eugenics.

37. TugendReICH. Die Gesundheitskarte. Berliner Med. Wochenschr. 1908.

38. WeINBERG. Methoden der Vererbungsforschung beim Menschen. Berl. Klin. Wochenschr. Jahrg. 491912. p. 646 en 677 .

_- Vererbung und Sociologie. Berl. Klin. Wochenschr. Jahrg. 491912 p. 1030

- - Ueber Vererbungsgesetze beim Menschen. Zeitschr. f. indukt. Abst. u. Vererb. lehre Bd. I 1909.

39. Westerbeek van Eerten, B. J. Eugenetiek. Historisch critisch overzicht. Diss.: Uitg. van Deutekom Varsseveld, 1920

40. Whetham, W. C. D. and C. The family and the Nation. London 1910.

41. Wintermans. Iets over de inrichting van stamboomen en stamboeken. Cultura org. Ned. inst. Landb.kunde 27 ste Jaargang 1915 p. 377

42. ZIEGLER, H. E. Die Vererbungslehre in der Biologie und in der Soziologie. Jena 1918 